International Research Journal of Management, IT \& Social Sciences
Available online at https://sloap.org/journals/index.php/irjmis/
Vol. 7 No. 2, March 2020, pages: 21-29
ISSN: 2395-7492
https://doi.org/10.21744/irjmis.v7n2.860

\title{
Evaluation of Intellectual Disability in Ecuador: A Challenge for Psychology
}

\author{
CrossMark
}

Crossick for undatises

Milan Ochoa Chang a

Osvaldo Jiménez Pérez de Corcho ${ }^{\mathrm{b}}$

Article history:

Submitted: 27 November 2019

Revised: 09 December 2019

Accepted: 31 January 2020

\section{Keywords:}

Ecuador;

evaluation;

intellectual disability;

psychology;

psychometric;

\begin{abstract}
One of the crucial aspects that Psychology assumes in the study of people with limitations in the Republic of Ecuador is the approach to intellectual disability. It is precisely and, within the framework of the implementation of the Manuela Espejo Solidarity Mission, it was necessary to address this issue of high social impact, this purpose the methodology used in conducting previous studies has taken as background in Cuba and Venezuela and of which the largest of the Antilles has been protagonist and manager. With this work, the objective has pursued, in the first instance, of reflecting on the complexity of the subject, due to the factors so diverse and dynamic that intervene in the classification of the different levels of intellectual affectation. Descriptively, the methods used in the 24 provinces of Ecuador have explained, verifying their effectiveness in the sample studied by the specialty. It has suggested, as a significant element, the implementation of new psychometric methods for subsequent studies, as well as the creation of diagnostic centers that detect, from earlier ages, people with intellectual disabilities for better treatment, intervention and quality improvement of life.
\end{abstract}

International research journal of management, IT and social sciences (C) 2020. This is an open access article under the CC BY-NC-ND license (https://creativecommons.org/licenses/by-nc-nd/4.0/).

Corresponding author:

Milan Ochoa Chang,

Universidad de Oriente, Santiago de Cuba, Cuba.

Email address: milan.ochoa@nauta.cu

Universidad de Oriente, Santiago de Cuba, Cuba

${ }^{\text {b }}$ Universidad Técnica de Manabí Portoviejo, Ecuador 


\section{Introduction}

Disability has had various denominations throughout history that have closely linked to the experiences of attention to this group. From a contemporary perspective, the historical evolution of intellectual disability has been divided into different stages. In the period before 1800, the concept of disability did not exist and people have considered abnormal, crazy, criminal, etc. From here, we point out the most relevant stages. Asylums, hospitals, and prisons have created between 1800 and 1870 for people with disabilities. In 1873 the first house of education was founded and the first educational actions for people with a disability arose.

Finally, from 1940 to the present, more realistic and optimistic attitudes have appeared due to the advancement of knowledge in intellectual disability (Rey de Sola et al., 2016). This advance has its best expression in the modification that has made in the same terminology that defines or leads reality. The term "mental retardation" has no longer accepted because it has a pejorative character that underlines the negative. The term has replaced by that of "intellectual disability" that doesn't irreversibly define or condemn the person, but rather alerts us to an evolutionary situation of special state, full of light and shadow, which, of course, also requires special attention. To limit problems and enhance capacities.

It is necessary, then, that we succeed in interpreting the contents contained in the term of intellectual disability, as the specialized organizations have recently defined after much reflection and debate because these contents have to help us adopt a determined and positive position towards a person (Adams \& Oliver, 2011; Menéndez \& Martinez, 2019). They will help us not only to define a diagnosis but, above all, to establish a global evaluation of all the wealth that adorns a person, to promote concrete solutions in each area or dimension, and to carry out permanent monitoring to control the results of our intervention. The institutions that lead this analysis and coordinate the discussion established with the help of many others around the world are the American Association on Mental Retardation (AAMR) and the International Association for the Scientific Study of Intellectual Disability (IASSID).

The conceptual vision that currently prevails in the field of intellectual disability is that which has primarily aimed at finding the right support for each person. For this, it establishes an intellectual disability evaluation process that includes three functions:

1) The diagnosis: determines the eligibility of a person to have considered as a person with intellectual disability.

2) Classification and description: identify the strengths and weaknesses of each individual in a series of dimensions or areas, in order to establish support needs.

The profile of support needs: identifies the necessary support to improve the functioning, the intensity of these supports, the people who have to provide them in different areas. Intellectual disability has defined as an entity that has characterized by the presence of:

1) Significant limitations in intellectual functioning

2) Significant limitations in adaptive behavior

3) Age of onset before 18 years

However, as already stated, intrinsically linked to this definition the global framework in which the person with disabilities is located is established. That is, the objective is not limited to defining or diagnosing intellectual disability but to progress in its classification and description, in order to identify the capabilities and weaknesses, the strengths and weaknesses of the person in a series of areas or dimensions that they cover different aspects of both the person and the environment in which they are. These dimensions or areas are as follows:

1) The most strictly intellectual capacities.

2) Adaptive behavior, both in the intellectual field and in the social field, or in the skills of daily life.

3) Participation, interactions with others and the social roles that the person plays.

4) Health in its widest expression; physical and mental.

5) The environmental and cultural context in which the person is included.

It is necessary to insist that the definition and analysis of these five dimensions have as main objective to establish and specify the support that should favor the functioning of each individual, like a specific person located in a specific environment and endowed with their problems and their qualities (Chang et al., 2020; Macías et al., 2018). The practical application of the definition proposed here has based on the following premises that serve us to establish, from the beginning, the ideological framework of our position in the face of intellectual disability: 
1) The limitations in the actual functioning must have considered taking into account the context of the environment's normal community in which peers of equal age and culture move.

2) For an evaluation to be valid, it must take into account cultural and linguistic diversity, as well as differences in communication and in sensory, motor and behavioral aspects.

3) Limitations and abilities often coexist in the same individual.

4) When describing the limitations, the most important objective should be the development of the profile of the necessary supports.

5) If appropriate personalized supports have offered for a sufficiently long period, the functioning of the person with intellectual disability will generally improve.

In view of this approach, so realistic and positive, it is clear that, from the evaluation that takes into account the five dimensions indicated, it was intended to seek the most appropriate support to achieve maximum individual functioning. Intellectual disability cannot have defined by a single element (Lardoeyt Ferrer, 2011; Maulik et al., 2011). It includes a set of conditions that shape it until it has expressed in a specific individual. Some of these conditions are inherent to the person; they are their strengths and weaknesses, which must have discovered in order to intervene properly. However, others are inherent in its environment and the resources it has or that it no longer has.

That is why the intellectual disability of an individual is not a fixed and unchanging entity. It has have modified by the biological growth and development of the individual and by the availability and quality of the support, he receives. In a constant and permanent interaction between the individual and his environment. The primary task is the detection of limitations and capabilities, depending on their age and future expectations. With the sole purpose of providing the necessary support in each of the dimensions or areas in which the person's life is expressed and exposed. According to DSM-5 and ICD-10, three basic criteria must have met to make a diagnosis of intellectual disability (Xiaoyan Ke \& Jing Liu, 2017):

1) A deficit of intellectual functions, such as reasoning, problem-solving, planning, abstract thinking, judgment, academic learning, and experience-based learning, confirmed by clinical evaluation and individualized standardized intelligence tests

2) A deficit of adaptive behavior that results in an inability to meet appropriate developmental and sociocultural standards for personal autonomy and social responsibility. Without continuous support, adaptive deficiencies limit functioning in one or more activities of daily life, such as communication, social participation and autonomous life in multiple environments such as home, school, work and community

3) The beginning of intellectual and adaptive deficits is during the period of development. The subtypes and their characteristics have already described at the beginning of this chapter. The diagnosis requires a thorough professional evaluation of intelligence and adaptive behavior. Often children with ID have referred to seek treatment because of their behavior and not their low intelligence. Moderate and severe forms of ID have detected earlier because developmental milestones have markedly delayed. The milder forms become evident during the first school years, because of academic difficulties, or even later, during adolescence.

A comprehensive evaluation should include detailed questions about:

1) The medical history of parents and family: genetic disorders, infections during pregnancy, prenatal exposure to toxins, perinatal damage, prematurity, and metabolic disorders

2) Development: language and motor skills, abilities social, compression and calculation

3) The environment in which the child grows: education, resources and family environment

Of the world's total, just over $40 \%$ of the population with disabilities is in the different countries of Latin America and the Caribbean. A situation is often unknown and ignored by many of the governments in office in this region. However, despite this traditional indifference to such a questioning reality, the Bolivarian Alliance for the Peoples of Our America (ALBA) decided to initiate a high-impact comprehensive care program in its constituent countries under Cuban technical leadership. As part of this effort, in 2006 the program of integral attention to the population with disabilities in Cuba has strengthened, while in mid-March 2008 the government of the Bolivarian Republic of Venezuela undertook the José Gregorio Hernández Solidarity Mission,

It includes, as a starting point, an exhaustive study of the entire population with some type of disability and genetic diseases in the national territory. The next countries that were part of this solidarity initiative were Bolivia and Nicaragua, at the end of 2009. In Bolivia, the Eustaquio "Moto" Méndez Solidarity Mission begins, while in Nicaragua it does the All with You Mission, both with a clinical study Genetic and psychosocial led by Cuban and local medical

Chang, M. O., \& Corcho, O. J. P. de. (2020). Evaluation of intellectual disability in Ecuador: a challenge for psychology. International Research Journal of Management, IT and Social Sciences, 7(2), 21-29.

https://doi.org/10.21744/irjmis.v7n2.860 
specialists, just as it was done in Venezuela. Similarly, thewas implemented in 2010 Live to Live program of comprehensive care for people with disabilities in St. Vincent and the Grenadines.

During the month of July 2009, the Manuela Espejo Solidarity Mission also began in Ecuador, structurally composed of four large blocks of action: diagnosis, response, prevention, and inclusion. The first block of action consists of the implementation of a biological and psychosocial, clinical and genetic diagnosis of the disabled population throughout the Ecuadorian territory, with special emphasis on the areas with the most difficult geographical access. This study was carried out between July 2009 and November 2010, during 487 days of intense work. In all the cantons of the 24 provinces of the country, by 314 Cuban, Venezuelan and Ecuadorian specialists. These medical specialists formed work teams with psychopedagogues, military and community leaders.

The Manuela Espejo Solidarity Mission is part of a social and clinical investigation to study and register georeferentially to all persons with disabilities; This allows us to know exactly who they are, how many they are, where they are, how they are and what they need, each and every one of the people with disabilities that inhabit the Ecuadorian territory. Because of this registration, the Joaquín Gallegos Lara program is born, which consists of the allocation of an economic bonus that has given to the person in charge of caring for a person with severe physical or intellectual disability in an environment of extreme poverty. The Mission was born thanks to the agreement signed between the republics of Ecuador and Cuba, where 229 Cuban medical specialists and 120 Ecuadorians completed the first diagnostic phase in the medical-scientific investigation of the causes of disabilities, giving a complete diagnosis, in areas that in the country have had an incipient development, such as clinical genetics.

The Manuela Espejo Solidarity Mission was initially a scientific-medical study to determine the causes of disabilities in order to delineate real state policies, covering multiple areas such as health, education and social welfare. This research arises in the absence of serious statistics that allow the public administration to make decisions or plan programs aimed at preventing or efficiently serving people with disabilities (Monje Vargas, 2013; Sinchi, 2016; Hepsiba \& Raju, 2017). For the first time in the country's history, doctors, geneticists, psychologists and health specialists, accompanied by military and community guides, moved to the most remote and remote places of the different provinces of Ecuador, in order to register and provide medical care to a population that has remained marginalized for many years during its existence.

From July 2009 to November 2010, the brigades of the Manuela Espejo Solidarity Mission visited 1,286 331 homes in 24 provinces and 221 cantons of Ecuador, studying and locating 294,611 people with disabilities, who are cared for comprehensively within the framework of the response phase.

In any case and in the general order, the intervention of the specialty of Psychology in research has aimed at:

1) Specifying, perfecting and deepening the diagnosis of intellectual disability, performing differential diagnosis.

2) Evaluate through psychological tests people who have not been able to define their diagnosis (degree of intellectual involvement).

3) Carry out a thorough assessment of people with intellectual disabilities who have offered resistance in the initial exploration carried out by the quartet psychopedagogue.

4) Offer individual psychological guidance, therapeutic talks to people who require it.

5) To guide the family about the management of people with disabilities by offering indications and activities that favor a better performance in functional skills.

6) To favor, in the necessary cases, the development of an adequate family environment contributing to improving its dynamics and functioning.

\section{Materials and Methods}

The work of the specialty in this pilot study has mostly aimed at people with intellectual disabilities. The evaluation of intellectual functioning is a crucial aspect to diagnose this disability, and should preferably have done by a psychologist. Limitations in intelligence must be considered alongside adaptive behavior; - participation, interaction and social roles; - physical and mental health; -and the context, because by themselves they are a necessary criterion, but not sufficient for the diagnosis.

Despite its limitations and the use and abuse that has made historically, the Intellectual Coefficient has considered as the best representation of the intellectual functioning of the person. For the psychometric evaluation, as a complement to the observation of the cases, various psychological instruments have used, among which we have the WISC and the WAIS. The WAIS (for over 18 years) and WISC (for children between 6 and 18 years), which have recognized by the World Health Organization, and in the country by the Ministry of Education, evaluate thought 
(abstraction function, conceptualization and verbal reasoning, logical-sequential, associative and mathematical thoughts). Spatial relations (perception and capacity of the organization and spatial integration referred to figurative and abstract contents). Calculation (mental calculation, numerical ability, attention, concentration, and mental application of arithmetic processes). Memory (to evoke content acquired in the learning process, as well as the ability to immediately retain semantic and symbolic content, orally and visually and working memory, that is, the ability to retain information in the school or work context). And Language (cultural level, learning acquired in the medium and level of language development, both comprehensive and expressive)

The diagnosis of intellectual disability is very complex, so in addition to the evaluation of the IQ with the aforementioned techniques, the Performing a comprehensive analysis of each individual based on techniques not less important as the interview and the observation of behavior, which was sometimes enriched with the review of pedagogical and medical reports in addition to school workbooks. The application of psychological tests should be a way to obtain information and not a trial. Diagnosis is a dynamic process, subject to change and to have perfected with educational practice. As part of a cross-sectional descriptive epidemiological investigation conducted in the Republic of Cuba in the period 2001-2003, intellectual disability was one of the main entities considered. The study included the entire Cuban population with disabilities residing in the national territory and within them, people with intellectual disabilities.

For the purposes of this article and the measurement, intellectual disability has considered significantly lower than the average intellectual functioning level, which usually coexists together with limitations in two or more areas of adaptive skills, such as communication, self-direction, health and safety, functional academic skills, free time and work.

In practical terms, disability manifests itself in the following levels of functioning:

Lightweight

Possesses schooling potentials up to ninth grade in special education.

- Susceptible job training.

- Able to integrate socially and labor.

Moderate

Has schooling potentials up to sixth grade in special education.

- Susceptible job training.

- Able to integrate socially and labor with help.

Severe

It has the potential to achieve functional adaptive skills.

- Susceptible learning of elementary labor techniques.

- Able to integrate socially and labor with help in a protected environment.

Deep

It has elementary verbal or extra verbal communication potentials.

- Dependent on activities of daily living.

- Their development possibilities have directly related to the opportunities offered to them both in the family and in the community.

\section{Results and Discussions}

At the conclusion of the fieldwork, the data has processed quickly and detailed information on the results has communicated to the community and its formal and informal leaders. The investigation also identified problems and restrictions that affected the living conditions of people with intellectual disabilities, but their solution and the different procedures used will be the subject of future publications.

Table 1

People with disabilities diagnosed

\begin{tabular}{lllll}
\hline Cantons & Intellectual & $\begin{array}{l}\text { Disability Major } \\
\text { Disability }\end{array}$ & $\begin{array}{l}\text { Without } \\
\text { disability }\end{array}$ & Total \\
\hline Cotopaxi & 154 & 30 & 8 & 192 \\
Carchi & 80 & 13 & 8 & 101
\end{tabular}

Chang, M. O., \& Corcho, O. J. P. de. (2020). Evaluation of intellectual disability in Ecuador: a challenge for psychology. International Research Journal of Management, IT and Social Sciences, 7(2), 21-29.

https://doi.org/10.21744/irjmis.v7n2.860 


\begin{tabular}{lllll} 
Esmeraldas & 157 & 20 & 27 & 204 \\
Sucumbíos & 107 & 23 & 24 & 154 \\
Imbabura & 48 & 18 & 6 & 72 \\
Napo & 59 & 15 & 11 & 85 \\
Manabi & 431 & 86 & 47 & 564 \\
Los Rivers & 135 & 34 & 19 & 188 \\
Orellana & 76 & 22 & 21 & 119 \\
Pastaza & 51 & 11 & 11 & 73 \\
Morona Santiago & 81 & 23 & 15 & 119 \\
Zamora & 88 & 13 & 12 & 113 \\
Loja & 200 & 36 & 15 & 251 \\
Azuay & 131 & 45 & 29 & 205 \\
Cañar & 70 & 18 & 9 & 97 \\
Bolívar & 38 & 9 & 8 & 55 \\
Chimborazo & 119 & 23 & 14 & 156 \\
Tungurahua & 90 & 33 & 15 & 138 \\
Santo Domingo & 112 & 39 & 18 & 169 \\
Gold & 202 & 68 & 31 & 301 \\
Santa Elena & 117 & 27 & 10 & 154 \\
Guayas & 1248 & 411 & 333 & 1992 \\
Galapagos & 8 & 7 & 2 & 17 \\
Pichincha & 277 & 131 & 107 & 515 \\
Total & 4079 & 1155 & 800 & 6034 \\
\hline
\end{tabular}

When the look at this table you can see that the patients evaluated by this specialty are mostly concentrated in the Guayas province, one of the most inhabited regions and with greater territorial extension. Where the population is concentrated and with access to the different services, such as health, It should be noted that in this region the study was extended for more than 2 months, which offered the possibility of following up on many of the people who required therapeutic treatments as well as their families.

The greatest number of patients seen is concentrated in intellectual disability (4079) as this is the central axis of the study and psychological evaluation. Followed by those patients with other disabilities evaluating 1155 children and adolescents (hearing, motor, mental and mixed disability) for affective-behavioral disorders that required psychological intervention and with a lower figure (800) those who had no disability. It should have noted that in this figure the learning disorders and behavioral disorders that in their differential diagnosis could lead to some extent with certain disabilities such as intellectual and mental ones play a predominant role.

Although the definition of the existence or not of intellectual disability is a complex task that, in many cases is not determined in a single evaluation. The determination of this disability, its presence or not in the individual is an aspect of the investigation or the definition of the degree of affectation; it is particularly difficult to establish this precision at an early age (from 0 to 5 years old) since it can be confused with the Delay in Psychomotor Development and other neurodevelopmental disorders. Among the people studied, there is the group in which the psychological evaluation was necessary to specify the degree of affectation that the research is framed in the "to be defined" cases, these were 997, which were classified according to the different levels. These people to whom the diagnosis could be defined were given the impressions taking into account, for example, the pathologies that necessarily involve intellectual disability and the severity of the neurological damage, since in no way was it intended to label the individual; remember that the diagnosis of intellectual disability is a dynamic process and therefore, it can be modified in favor or against positive growth but never eliminated since it is, in fact, a permanent affectation.

Next, the distribution of cases seen with an intellectual disability according to the degree of involvement is plotted in figure 1. 


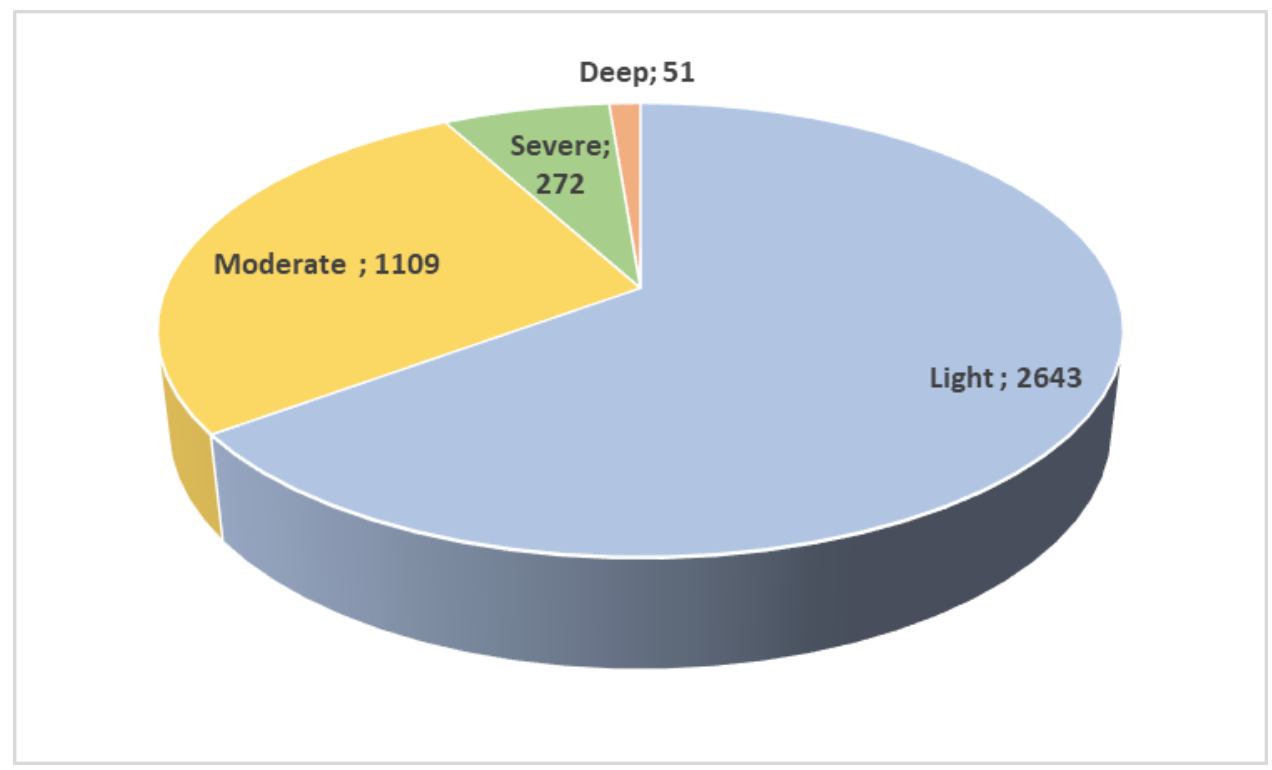

Figure 1. Degrees of intellectual affectation

This graph shows, within intellectual disability, a predominance of light degrees (2643) over moderate (1109) and severe (272). It is given because in these levels of intellectual involvement its detection is more complex, especially in subcultural environments where there is an underestimation, which tends to confuse the diagnosis, for this the timely evaluation of the psychologist is needed with the application of different psychological instruments. The data thrown coincide with those issued in the world literature where the milder grades predominate over the most severe, there is no predominance of any of the provinces in this result, and its statistical behavior coincides with the expected.

In order to deepen the diagnosis of intellectual disability we plan the application of the WISC and WAIS tests, fundamentally, although other complementary and less complex techniques have also used, these have described below in Table 2.

Table 2

Tests Applied diagnoses

\begin{tabular}{ll}
\hline Psychological tests & Total \\
\hline Wisc & 625 \\
Wais & 42 \\
Other tests & 2299 \\
Total & 1092 \\
\hline
\end{tabular}

In the data described above, it has observed that in only 667 people the precise search of the IQ was necessary, mostly under 16 years of age, ages in which it becomes very complex plus the diagnosis and where it has regularly evidenced when the child begins to have difficulties in academic learning (Paz y Miño \& López Cortés, 2015). In the course of the investigation and given the need of some patients to have treated by the psychologist, psychological treatments had to have provided in different modalities taking into account the different problems that coexist in the individual with limitations, their family and school environment; for this, we rely on the analysis of the following table:

Chang, M. O., \& Corcho, O. J. P. de. (2020). Evaluation of intellectual disability in Ecuador: a challenge for psychology. International Research Journal of Management, IT and Social Sciences, 7(2), 21-29. 
Table 3

Interventions carried out

\begin{tabular}{ll}
\hline Treatment Modality & No. of Treatments \\
\hline Family & 5842 \\
Psychological orientations Individual psychological orientations & 2858 \\
Family dynamics & 1244 \\
Psychotherapies & 823 \\
Total & 10767 \\
\hline
\end{tabular}

The data that reflected this table show, the most valuable significance of the intervention of the specialty of Psychology. Within the investigation and is to be able to guide families and people with disabilities by the affectation in the dynamics that usually entails the birth of a child with a disability and by the need for the active participation of each household member in the development and improvement of the quality of life of these people. Many of these people have never received specialized guidance, especially in areas of very difficult access. It is important to reflect here the predominance of family psychological orientations, followed by the individual ones, which shows that the total number of patients treated, has given some alternative psychological treatment. The continuity of the treatment was oriented in the consultation itself through the possibilities offered in some regions by the community itself. Some of the cases treated were interconsultated with the specialties were part of the multidisciplinary team, (Neuropediatrics, Neurophysiology, and Otolaryngology) which guaranteed a more comprehensive evaluation of the patient, offering us better tools in their orientation and treatment.

\section{Conclusion}

From the present study, the following conclusions have been reached: The province of Guayas was the one with the highest number of cases evaluated, thus responding to its population density and territorial extension, as well as the duration of the mission in that region. Within the intellectual disability attended in a Psychology clinic, there was a predominance of people with light and moderate intellectual disabilities. Psychological treatments have offered, among which is the most prevalent, family psychological orientations. Access to psychological evaluation has significantly limited by the small number of specialists in this branch in the public sector. There is difficulty in the diagnosis of Intellectual Disability; a large part of the family does not know, accurately, the diagnosis of their children. There is a growing need for family guidance aimed at formulating educational strategies in this area. From the above, it has been summarized that the specialty of Psychology is necessary for the integral attention of the personality of people with disabilities.

\section{Conflict of interest statement}

The authors declared that they have no competing interests.

\section{Statement of authorship}

The authors have a responsibility for the conception and design of the study. The authors have approved the final article.

\section{Acknowledgments}

We are grateful to two anonymous reviewers for their valuable comments on the earlier version of this paper. 


\section{References}

Adams, D., \& Oliver, C. (2011). The expression and assessment of emotions and internal states in individuals with severe or profound intellectual disabilities. Clinical psychology review, 31(3), 293-306. https://doi.org/10.1016/j.cpr.2011.01.003

Chang, M. O., Peralta, A. O., \& de Corcho, O. J. P. (2020). Training with cognitive behavioral techniques for the control of precompetitive anxiety. International journal of health \& medical sciences, 3(1), 29-34. https://doi.org/10.31295/ijhms.v3n1.121

Hepsiba, -, \& Raju, M. (2017). Intellectual disability. International Research Journal of Engineering, IT \& Scientific Research, 3(5), 34-43.

Ke, X., \& Jing, LIU (2017). Intellectual disability Translation of IRARRÁZAVAL, M., MARTIN, A., PRIETO-TAGLE, F. and FUERTES, O.). In KING, Joseph. IACAPAP Child and Adolescent Mental Health Manual, 1-28.

Lardoeyt Ferrer, R. (2011). Estudio psicopedagógico, social y clínico genético de la discapacidad en el ALBA. Revista Cubana de Genética Comunitaria, 5(2), 6-9.

Macías, EIP, Cedeño, HAC, \& Chávez, GMR (2018). Importance of Improving Resilience in Teaching-Learning Process of Students with Disabilities. International Research Journal of Management, IT and Social Sciences, 5 (2), 120-128. Retrieved from https://sloap.org/journals/index.php/irjmis/article/view/59

Maulik, P. K., Mascarenhas, M. N., Mathers, C. D., Dua, T., \& Saxena, S. (2011). Prevalence of intellectual disability: a meta-analysis of population-based studies. Research in developmental disabilities, 32(2), 419-436. https://doi.org/10.1016/j.ridd.2010.12.018

Menéndez, E. S., \& Martinez, M. E. M. (2019). Problems of learning and pedagogical intervention. International Journal of Social Sciences and Humanities, 3(2), 105-111. https://doi.org/10.29332/ijssh.v3n2.301

Monje Vargas, J. A. (2013). Mission-Manuela Espejoll, paradigm of solidarity turned into a state policy in Ecuador. Revista Cubana de Salud Pública, 39(3), 598-608.

Paz y Miño, C., \& López Cortés, A. (2015). Analysis of people with disabilities in mestizo and indigenous population of Ecuador. Voice, 7-18.

Rey de Sola, M.J., Caminos, M.R., García, M.T., Cabrera, R.M., \& Dosouto, H.A. (2016). Personas con discapacidad intelectual. Fundación Juan Ciudad, ISBN 84-88756-31-3.

Sinchi, YTS (2016). Social development of people with disabilities in Ecuador (Doctoral dissertation, UNIVERSITY OF CUENCA).

Chang, M. O., \& Corcho, O. J. P. de. (2020). Evaluation of intellectual disability in Ecuador: a challenge for psychology. International Research Journal of Management, IT and Social Sciences, 7(2), 21-29. 